\title{
Comparison of effects of alcaftadine and olopatadine on conjunctival epithelium and eosinophil recruitment in a murine model of allergic conjunctivitis
}

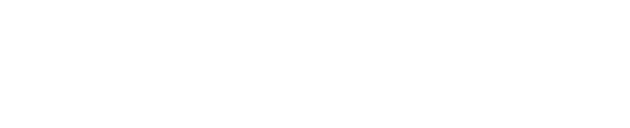

Santa J Ono'

Keith Lane ${ }^{2}$

'Emory University School of Medicine and Emory Eye Center, Dobbs Ocular Immunology Laboratories, Atlanta, GA, USA; ${ }^{2}$ Ora Inc., 300 Brickstone Square, Andover,

MA, USA
Correspondence: Keith Lane Ora Inc., 300 Brickstone Square, Andover, MA 0I8I0, USA

Tel + I 978-685-8900

$\mathrm{Fax}+1$ 978-689-0020

Email klane@oraclinical.com
Background: Antihistamines constitute the first line of therapy for allergic conjunctivitis, and are safe and effective in relieving the signs and symptoms of ocular allergy. Despite this, they are less effective than some other drugs in relieving delayed symptoms of allergic conjunctivitis. Recent evidence suggests that changes in the conjunctival epithelium may underlie aspects of delayed reactions. In this study we compared two antihistamines, olopatadine and alcaftadine, for their ability to modify epithelial cell changes associated with allergic conjunctivitis at time points selected to reflect late-phase reactions.

Methods: Studies employed a modified conjunctival allergen challenge model. Sensitized mice were challenged with topical allergen with or without drug treatments. Treatment groups were assayed for acute-phase (15 minutes) and delayed-phase (24 hours) responses. Groups were scored for allergy symptoms (redness, itch, tearing, and edema) and for conjunctival mast cell numbers. Delayed-phase groups were also examined for eosinophil numbers and for tight junctional protein expression.

Results: Olopatadine-treated and alcaftadine-treated animals had similar efficacy profiles and mast cell numbers, suggesting both were effective at ameliorating symptoms of the acute phase. In contrast, alcaftadine-treated animals had significantly lower conjunctival eosinophil infiltration than either controls or olopatadine-treated animals. Allergen challenge caused a significant decrease in expression of the junctional protein, $\mathrm{ZO}-1$, and this decrease was prevented by alcaftadine but not by olopatadine.

Conclusion: Alcaftadine displays therapeutic properties beyond its antihistamine action. These include an ability to reduce conjunctival eosinophil recruitment, and a protective effect on epithelial tight junction protein expression.

Keywords: alcaftadine, olopatadine, ocular allergy

\section{Introduction}

Allergic conjunctivitis affects over $20 \%$ of the general population, and includes seasonal allergic conjunctivitis and perennial allergic conjunctivitis. ${ }^{1,2}$ The varying manifestations of allergic conjunctivitis reflect a Type 1 , Type 4, or combined IgEdependent hypersensitivity inflammatory response to an allergen leading to activation of mast cells, basophils, eosinophils, and other mediators. ${ }^{3}$ Allergen load, degree of dilution within the tear film, expression of adhesion molecules by epithelial cells within the ocular surface, and several other environmental and physiological factors all dictate the initiation and magnitude of the allergic response. By affecting passage 
towards the basement membrane, where allergen proteins cross-link with IgE and incite the allergic cascade, these processes also represent potential upstream targets of antiallergy treatment.

One of the protective elements of the ocular surface that must be overcome in order for an allergen to elicit a positive response are the tight junctions of the conjunctival epithelium. Tight junctions are cell membrane protein complexes that link the cytoskeletons of adjacent epithelial cells for adhesion and stability. They comprise occludin and claudin transmembrane proteins that form a selectively permeable seal and regulate paracellular transport. ${ }^{4}$ Within healthy conjunctiva, tight junctions act as a nearly impermeable barrier and allow the passage of only nutrients and water, while blocking the passage of toxins, microorganisms, and allergens. In diseased conjunctiva, the function and organization of the tight junction is diminished, and the expression of junctional proteins is disrupted, thereby compromising the gatekeeping function of the epithelial layer. ${ }^{5}$

Recent work has provided evidence of a role for tight junctions in the pathology of allergy. Several common allergens have been implicated in changes in key tight junction proteins. For example, house dust mite fecal pellets have been shown to contain proteolytic enzymes that break down occludins, such as zonula occludens 1 (ZO-1). ${ }^{6}$ This proteolysis leads to tight junction cleavage and increased epithelial permeability. ${ }^{6}$ Similarly, pollen peptidases from several species have been shown to degrade epithelial tight junctions, either directly or indirectly, based upon the loss of occludin, claudin-1, and ZO-1 immunofluorescent staining. ${ }^{7}$ In comparisons of patients with seasonal allergic conjunctivitis and normal controls, the patients with seasonal allergic conjunctivitis exhibit a downregulation of epithelial cell adhesion proteins and cytoskeletal elements. ${ }^{5}$ Collectively, these data suggest that changes in tight junction protein expression, assembly, or both, may participate in the etiology of conjunctival allergy.

Steroids are typically a secondary choice for treatment of allergic conjunctivitis. ${ }^{8}$ They are effective in treating chronic allergy, but have significant side effects, including a risk of increased intraocular pressure. Several in vitro studies have shown that glucocorticoids exert a stabilizing effect on tight junctions and on epithelial permeability. ${ }^{9,10}$ While a specific connection between steroid effects on epithelial tight junctions and their efficacy in late-phase conjunctivitis remains to be established, these results are intriguing in light of the data connecting allergic conjunctivitis and changes in tight junctional proteins.
Alcaftadine is a tricyclic piperidine aldehyde that exhibited antihistamine activity in several well established in vivo models. ${ }^{11}$ It also showed anti-inflammatory activity in the alleviation of eosinophil infiltration in a guinea pig model of allergic conjunctivitis. ${ }^{12}$ In addition, alcaftadine has a unique spectrum of histamine receptor specificity: it has high affinity for both $\mathrm{H}_{1}$ and $\mathrm{H}_{2}$ histamine receptors (3.1 and $58 \mathrm{nM} \mathrm{K}_{\mathrm{i}}$, respectively), and also exhibits $\mathrm{H}_{4}$ receptor antagonism in vitro. ${ }^{12}$ Collectively, these observations suggest that alcaftadine may have properties that distinguish it from other antihistamines.

The purpose of this study was to compare the effects of alcaftadine $0.25 \%$ and an active control (olopatadine $0.1 \%$ ophthalamic solution; Alcon Laboratories, Fort Worth TX) on the expression of key tight junction proteins within a murine model of allergic conjunctivitis. Like alcaftadine, olopatadine has been shown to have anti-inflammatory properties in vitro. ${ }^{13,14}$ The expression of two junctional proteins, ZO-1 and E-cadherin, were determined in both treated and untreated allergen-challenged mouse eyes using confocal microscopy. In addition, the extent of eosinophil recruitment was measured in all experimental groups.

\section{Materials and methods}

\section{Animals}

Eighty BALB/c mice supplied by Jackson Laboratories (Bar Harbor, ME) were used in this study. The mice were housed in the facilities of the Woodruff Health Sciences Center of Emory University (Atlanta, GA) and maintained in accordance with the Association for Research in Vision and Ophthalmology Resolution on the Use of Animals in Research and internal animal use guidelines.

Sixteen mice were enrolled per treatment arm. Eight mice per treatment arm were evaluated for early-phase assessment (clinical signs and symptom and mast cell density) and eight mice per arm were evaluated for delayed-phase assessments (eosinophil recruitment, tight junction protein expression) as shown in Table 1. All animals received a thorough examination to ensure that there was no sign of pre-existing ocular inflammation. The five treatment arms were: naïve (no sensitization, no allergen challenge [NS/NC]); sensitized, challenged (no treatment $[\mathrm{S} / \mathrm{C}])$; sensitized, challenged, vehicle-treated (vehicle); sensitized, challenged, olopatadine-treated (olopatadine); and sensitized, challenged, alcaftadine-treated (alcaftadine). The naïve group provided a baseline to assess the effects of challenge, while the vehicle group ensured that any effects observed in out two treatment groups were due to the active agents. Following experimental treatments (at times 
indicated), animals were euthanatized by cervical dislocation and tissues were removed for assay.

\section{Test articles/randomization}

Alcaftadine $0.25 \% \mathrm{w} / \mathrm{v}$ ophthalmic solution was the experimental treatment, olopatadine $0.1 \% \mathrm{w} / \mathrm{v}$ ophthalmic solution was used as an active control, and alcaftadine ophthalmic solution vehicle was used as a placebo control. This vehicle comprised isotonic saline buffered with sodium phosphate and ethylenediamine tetraacetic acid to $\mathrm{pH}$ 7.4. The vehicle also contained $0.005 \% \mathrm{w} / \mathrm{v}$ benzalkonium chloride as a preservative. Vistakon Pharmaceuticals, LLC (Jacksonville, FL) provided the alcaftadine ophthalmic stock solution and vehicle stock solution. A technician not involved in the study performed all masking and randomization procedures. Prior to sensitization, mice were randomized to one of five treatment arms shown in Table 1.

\section{Sensitization (days I-I4)}

Conjunctival allergen challenge involves direct ocular instillation of antigen in animals sensitized to elicit an allergic response. Mice were injected intraperitoneally with $1 \mathrm{mg}$ of aluminum hydroxide conjugated with short ragweed pollen extract (2000 AU/mouse; ALK Laboratories Round Rock, TX) on days 1 and 14. Concomitantly, aluminum hydroxideconjugated short ragweed pollen extract $1000 \mathrm{AU} / \mu \mathrm{L}$ was topically administered into the eye on days $1,2,3,7$, and 14 ( $25 \mu \mathrm{g} /$ eye). Thereafter, mice were topically challenged in both eyes once per week with short ragweed pollen extract $1000 \mathrm{AU} / \mu \mathrm{L}$ without aluminum hydroxide.

\section{Challenge (days 28-30)}

Four weeks after the initial sensitization, mice were challenged bilaterally by instilling affinity-purified short ragweed

Table I Treatment Group Properties

\begin{tabular}{|c|c|c|c|c|c|}
\hline Group & Sensitization & $\begin{array}{l}\text { Allergen } \\
\text { challenge }\end{array}$ & Treatment & $\begin{array}{l}\text { Early } \\
\text { phase } \\
\text { n }\end{array}$ & $\begin{array}{l}\text { Late } \\
\text { phase } \\
\text { n }\end{array}$ \\
\hline I & - & - & $\begin{array}{l}\text { No treatment } \\
\text { (NS/NC) }\end{array}$ & 8 & 8 \\
\hline 2 & + & + & $\begin{array}{l}\text { No treatment } \\
(\mathrm{S} / \mathrm{C})\end{array}$ & 8 & 8 \\
\hline 3 & + & + & $\begin{array}{l}\text { Alcaftadine } \\
\text { vehicle }\end{array}$ & 8 & 8 \\
\hline 4 & + & + & Olopatadine $0.1 \%$ & 8 & 8 \\
\hline 5 & + & + & alcaftadine $0.25 \%$ & 8 & 8 \\
\hline
\end{tabular}

Abbreviations: $N S / N C$, no sensitization, no challenge (naïve animals); $S / C$, sensitized, challenged. pollen $0.5 \mathrm{mg} / \mathrm{mL}$ topically ( $10 \mu \mathrm{L} /$ eye $)$ for three consecutive days. Control mice were sensitized in a similar manner and challenged using antigen solution. The specificity of the allergic responses was confirmed by challenging sensitized mice with experimentally irrelevant antigens. After the final challenge, clinical responses were recorded within the first 30 minutes and graded for symptoms of allergic conjunctivitis.

\section{Dosing (days 28-30)}

Dosing was performed prior to challenge on the three consecutive challenge days that comprised the final three days of the study. One eye received study drug and the other eye received placebo. Ten microliters of the assigned test article were administered topically twice, ie, at two hours and at one hour prior to the final topical challenges. The test article was administered according to the randomization scheme shown in the table1. For the delayed-phase group, two additional doses were given at hours 1 and 2 after challenge prior to sacrifice 24 hours after challenge.

\section{Early-phase assessments}

Following the final allergen challenge, ocular symptoms were evaluated in a double-blinded fashion and graded on a $0-4$ scale by an ophthalmologist unaware of the group to which each mouse was randomized. Mice were placed in a laminar flow hood under ambient light conditions for evaluation.

The behavioral responses of the mice were continuously recorded between 10 and 15 minutes after challenge, and their squinting/face-washing score was graded based on numbers of continuous actions. The mice were videotaped to allow cross-checking of these numerical scores.

After the final challenge, conjunctival edema, lid edema, redness, and tearing were evaluated 15 minutes after challenge. The cumulative clinical score was calculated as the sum of the scores of each of these four parameters (0-16). A more detailed assessment of the criteria used has been described elsewhere. ${ }^{15}$

Mice in the early-phase group were sacrificed 30 minutes after conjunctival allergen challenge and tissues were processed for mast cell density analysis. Collected tissues were fixed in $4 \%$ paraformaldehyde and embedded in historesin (Leica Instruments GmbH, Nussloch, Germany). Serial sagittal sections $(3 \mu \mathrm{m})$ were stained with toluidine blue for mast cell identification. Three consecutive tissue sections from each eye were examined, and mast cells were 
counted under a $200 \times$ field microscope in a double-blinded fashion.

\section{Delayed-phase assessments}

Mice in the delayed-phase group were sacrificed at 24 hours after conjunctival allergen challenge. Collected tissues were fixed, embedded, and cut as described above. Tissue sections were stained with Giemsa and hematoxylin and eosin. Eosinophil cell counts were determined in a double-blinded fashion as described for mast cell counting. For confocal microscopy, serial frozen sections ( $10 \mu \mathrm{m}$ in thickness) were acetone fixed at $-20^{\circ} \mathrm{C}$ for 10 minutes, then equilibrated in phosphate-buffered saline. Eosinophil infiltration was imaged by staining with an antibody to the eosinophil-specific major basic protein (antibody provided by HC Lee, Mayo Clinic, Rochester, MN) followed by anti-rat IgG fluorescein isothiocyanate conjugate (BD Pharmingen, San Diego, CA). Sections were counterstained for nucleic acid using Vectashield mounting medium with propidium iodide (Vector Labs, Burlingame, CA). Sections were cut and prepared similarly for ZO-1 and E-cadherin imaging. Sections were incubated with rabbit anti-ZO-1 and rat anti-E cadherin (both antibodies from Invitrogen, Carlsbad, CA). Primary antibodies were visualized with goat anti-rabbit IgG coupled with Alexa-568 (ZO-1) and goat anti-rat IgG coupled with Alexa-488. Both secondary antibodies were obtained from Invitrogen.

All of the images for ZO-1 and E-cadherin were captured using an Olympus FluoView fluorescence microscope (Olympus America Inc, Center Valley, PA). Fluorescence intensity values of ZO-1 and E-cadherin were measured using Image-Pro Plus software (version 6.2; Media Cybernetics Inc, Bethesda, MD, http://www.mediacy.com/). This program uses an automated algorithm to identify regions of specific staining and calculates density of fluorescence signal. Eight such determinations were averaged, and the resulting data were analyzed using GraphPad PRISM version 5.00 (GraphPad, San Diego, CA). Statistical significance was assessed by comparing all treatment groups using Tukey's multiple comparison test. A $P$ value of less than 0.05 was considered significant.

\section{Results}

\section{Early-phase assessments}

Sensitization and challenge induced significant increases in allergic signs and symptoms, including tearing and discharge, lid edema, conjunctival chemosis, and conjunctival redness $(P<0.001$, Figure 1A). Although both olopatadine and alcaftadine were numerically superior to the $\mathrm{S} / \mathrm{C}$ group, neither agent was statistically superior. Mast cell counts showed no significant differences between treatment groups (Figure 1B).

\section{Late-phase assessments}

Changes in conjunctival eosinophil number were examined by two methods. Tissue sections from each of the five treatment groups were stained for major basic protein, a specific eosinophil cell marker. Figure 2 shows the level of eosinophil staining is dramatically increased in both $\mathrm{S} / \mathrm{C}$ (Figure 2B) and vehicle (Figure 2C) conjunctiva. This increase is reduced in animals receiving olopatadine (Figure 2D) or alcaftadine (Figure 2E). Tissue sections were also stained for eosinophil cell counting; data from
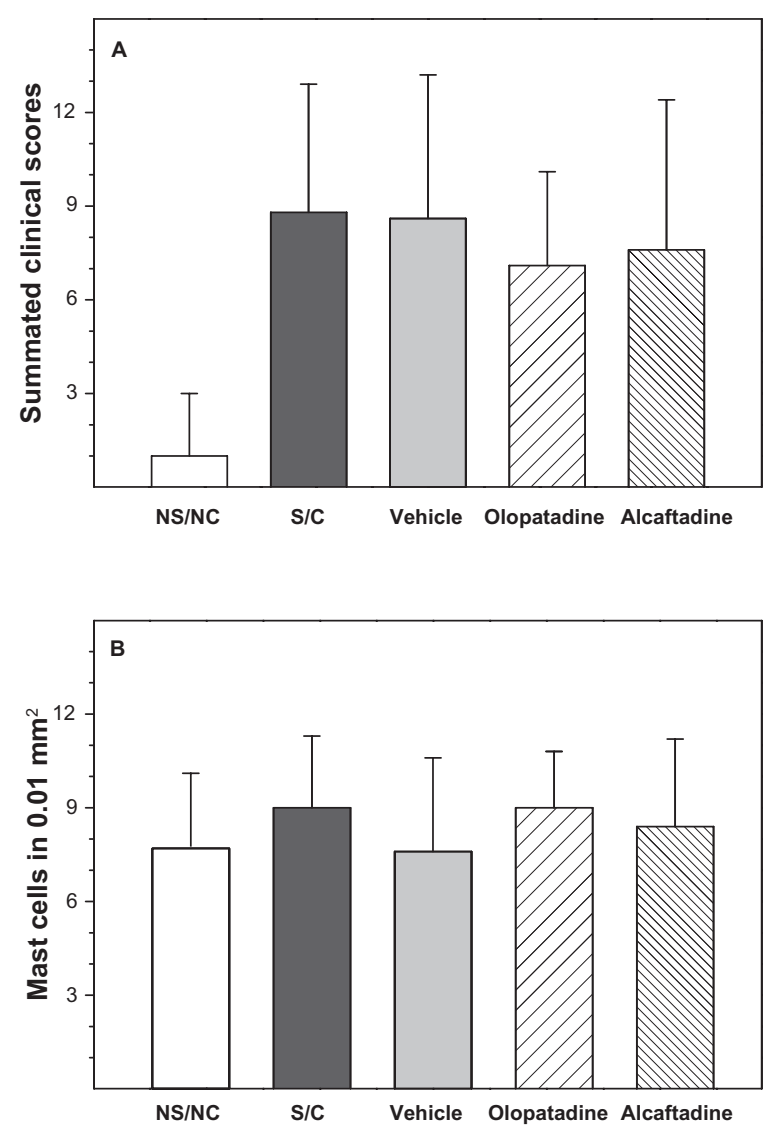

Figure I Acute-phase assessments. Measures of acute response in the modified conjunctival allergen challenge assay. A) Mean values of summated symptom scores for five treatment groups. Symptoms include tearing, lid edema, conjunctival chemosis, and conjunctival redness. All treatment groups are significantly different from untreated (NS/NC, $P>0.001$ ). B) Mast cell counts from three consecutive conjunctival tissue sections observed under a $200 \times$ field microscope. No significant differences were observed between groups. Error bars indicate standard error in both (A and B).

Abbreviations: NS/NC, no sensitization, no challenge (naïve animals); S/C, sensitized, challenged; vehicle, sensitized, challenged, drug vehicle only; olopatadine, sensitized, challenged, $0.1 \%$ topical olopatadine; alcaftadine, sensitized, challenged, $0.025 \%$ topical alcaftadine. 

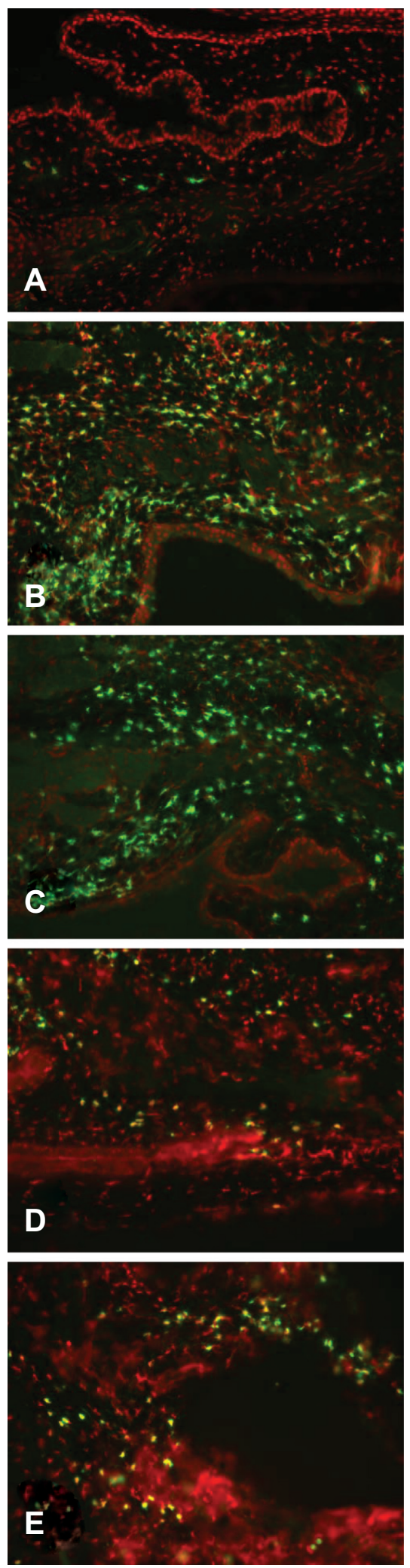

Figure 2 Eosinophil infiltration of conjunctiva. Confocal images of tissue sections from each treatment group stained for eosinophil-specific major basic protein (green) and counterstained with propidium iodide (red). A) No sensitization, no challenge (NS/NC; naïve animals); B) Sensitized, challenged (S/C); C) $S / C+$ drug vehicle; D) $\mathrm{S} / \mathrm{C}+0.1 \%$ topical olopatadine; E) $\mathrm{S} / \mathrm{C}+0.025 \%$ topical alcaftadine. Major basic protein staining is most pronounced in sensitized, challenged animals without drug treatment (B and $\mathbf{C})$. these experiments are shown in Figure 3. Sensitization and challenge induced a significant increase in eosinophils in the conjunctiva compared with the NS/NC group $(P<0.001)$. Treatment with alcaftadine $0.25 \%$ significantly inhibited eosinophil recruitment to the conjunctiva $(P<0.001)$ while treatment with olopatadine $0.1 \%$ did not. A direct statistical comparison between olopatadine $0.1 \%$ and alcaftadine $0.25 \%$ treatment groups found that alcaftadine $0.25 \%$ was statistically superior to olopatadine $0.1 \%$ for prevention of eosinophil recruitment $(P<0.05)$. Alcaftadine $0.25 \%$ was also statistically superior to vehicletreated eyes for prevention of eosinophil recruitment to the conjunctiva $(P<0.001)$.

Expression of e-cadherin and ZO-1 was also examined with immunofluorescent staining and confocal microscopy (Figure 4). These images were used to derive a quantitative comparison of expression levels in each tissue (Figures 5A and $5 \mathrm{~B}$ ). The ZO-1 expression level was significantly decreased in the $\mathrm{S} / \mathrm{C}$ group compared with the NS/NC control $(P \leq 0.05)$. Alcaftadine $0.25 \%$ was statistically better at preventing this loss of ZO-1 expression compared with the $\mathrm{S} / \mathrm{C}$ group $(P<0.05)$ and was not statistically different from the NS/NC control. Treatment with olopatadine $01 \%$ did not prevent ZO-1 expression loss. There was no significant difference in E-cadherin expression levels between the $\mathrm{NS} / \mathrm{NC}$ and $\mathrm{S} / \mathrm{C}$ groups, but a mean decrease was seen in the $\mathrm{S} / \mathrm{C}$ group (Figure 5B). Alcaftadine $0.25 \%$ was statistically

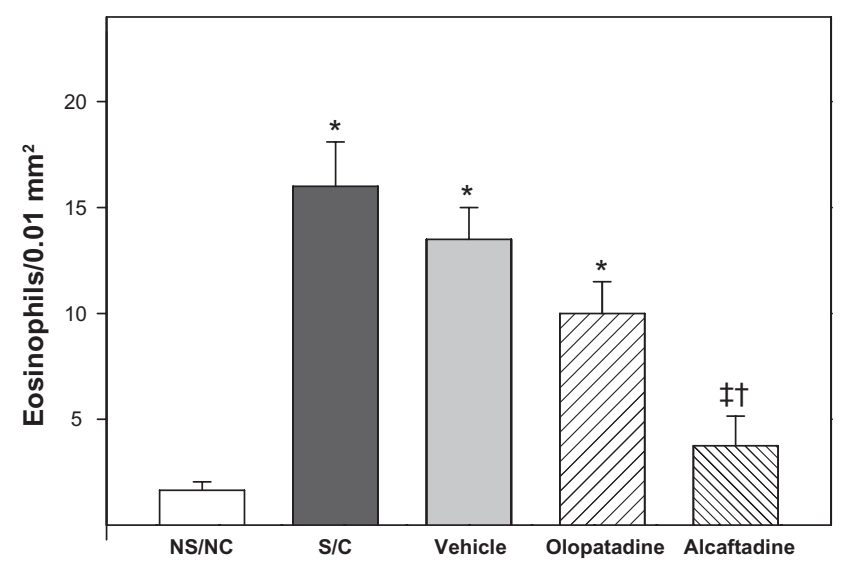

Figure 3 Quantitation of eosinophil infiltration. Sections stained with Giemsa and hematoxylin and eosin to allow for direct counting of eosinophils; counts are from three consecutive conjunctival tissue sections. The S/C, vehicle, and olopatadine treatment groups are all significantly different from NS/NC $(* P<0.01)$. The alcaftadine group is not significantly different from NS/NC. Olopatadine is not significantly different from $S / C$ or from vehicle, but alcaftadine is significantly different from both of these treatments $(\ddagger P<0.01)$. The alcaftadine group is also significantly different from the olopatadine group $\left({ }^{\dagger} P<0.05\right)$.

Abbreviations: NS/NC, no sensitization, no challenge (naïve animals); S/C, sensitized, challenged; vehicle, sensitized, challenged, drug vehicle only; olopatadine, sensitized, challenged, $0.1 \%$ topical olopatadine; alcaftadine, sensitized, challenged, $0.025 \%$ topical alcaftadine. 

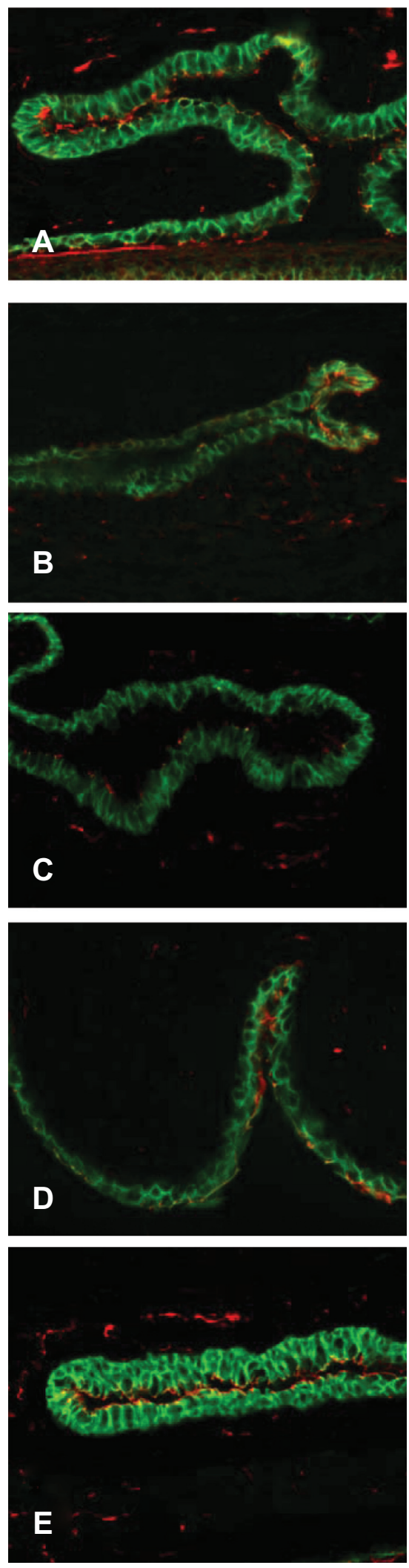

Figure 4 Labeling of tight junctional proteins in conjunctiva. Immunofluorescent staining of ZO-I (red) and E-cadherins (green) in tissue sections from five treatment groups. A) No sensitization, no challenge (naïve animals); B) Sensitized, challenged; C) Sensitized, challenged, drug vehicle only; D) Sensitized, challenged, 0.1\% topical olopatadine; E) Sensitized, challenged, $0.025 \%$ topical alcaftadine. Note decreased staining in sensitized, challenged animals without drug treatment (B and $\mathbf{C})$.
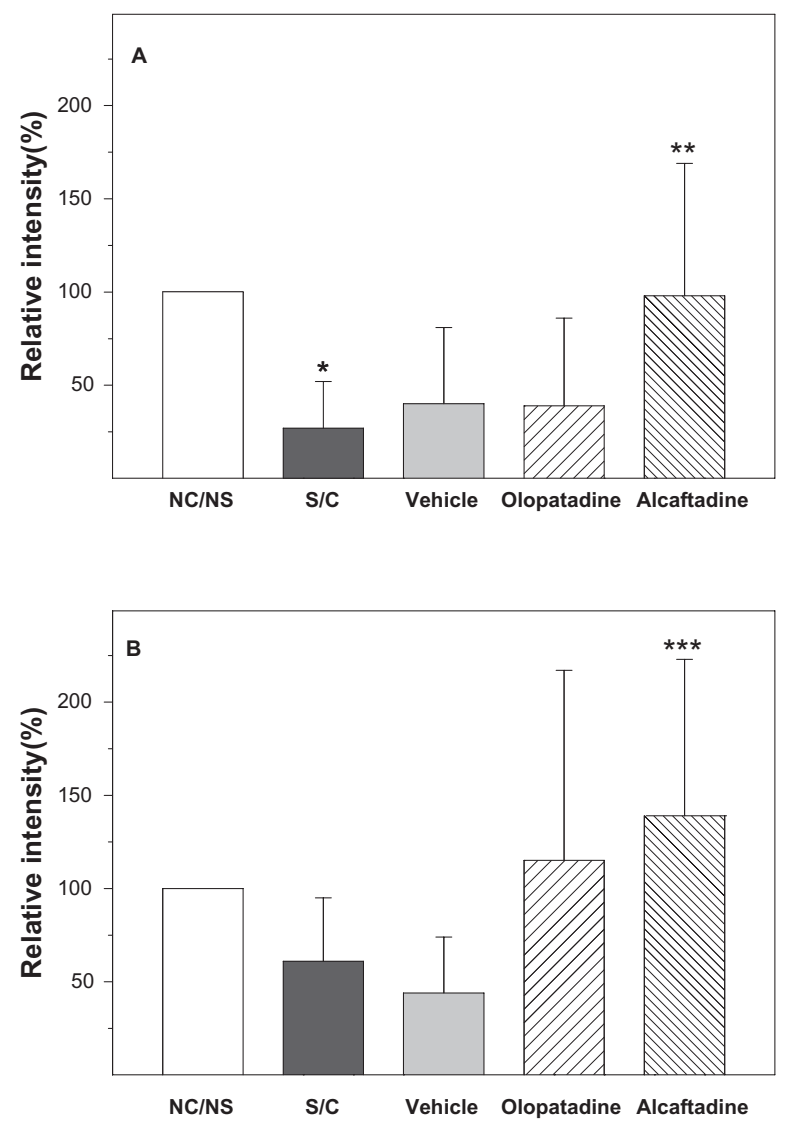

Figure 5 Alcaftadine prevents conjunctival allergen challenge-associated changes in ZO-I and E-cadherin in conjunctival epithelium. Confocal images were used to calculate relative expression of tight junction proteins in five groups. ZO-I expression was significantly decreased in sensitized, antigen-challenged $(\mathrm{S} / \mathrm{C})$ tissue compared with control tissue (5A, $* P \leq 0.05)$. Both alcaftadine and olopatadine prevented this decrease, but only alcaftadine values were significantly different from the $\mathrm{S} / \mathrm{C}$ groups ( $* * P \leq 0.05$ ). Differences in fluorescence intensity in $\mathrm{E}$-cadherin staining (5B) between naïve and antigen-challenged groups were not significant, but treatment did result in trend of lower expression that was reversed in both active treatment groups. The only comparison that did reach the level of significance was the increase seen in alcaftadine-treated samples compared with the $S / C+$ vehicle group $(* * * P \leq 0.05)$.

Abbreviations: NS/NC, no sensitization, no challenge (naïve animals); S/C, sensitized, challenged; vehicle, sensitized, challenged, drug vehicle only; olopatadine, sensitized, challenged, $0.1 \%$ topical olopatadine; alcaftadine, sensitized, challenged, $0.025 \%$ topical alcaftadine; ZO-I, zonula occludin I.

superior at preventing loss of E-cadherin expression compared with the $\mathrm{S} / \mathrm{C}$ group $(P<0.05)$. Treatment with olopatadine $0.1 \%$ did not result in a statistically significant change from the $\mathrm{S} / \mathrm{C}$ control. E-cadherin expression increased in both active treatment arms.

\section{Discussion}

In this study, a murine model of allergic conjunctivitis was used to examine the effects of alcaftadine and olopatadine on several aspects of chronic conjunctivitis. Rather than examining a range of concentrations, we tested each of these agents at the concentrations used clinically. Overall, sensitization and challenge induced a robust allergic response, 
evidenced by increased clinical signs and symptoms, increased eosinophilia, and decreased expression of ZO-1 and E-cadherin tight junction markers. Although there was no statistical significance, mean symptom scores were reduced in both active treatment arms (olopatadine $0.1 \%$ and alcaftadine $0.25 \%$ ).

Alcaftadine significantly inhibited eosinophil recruitment compared with both the S/C and olopatadine $0.1 \%$ treatment groups. While the mechanism for this unique action of alcaftadine is unknown, it has been shown to antagonize $\mathrm{H}_{2}$ and $\mathrm{H}_{4}$ histamine receptors in addition to its $\mathrm{H}_{1}$ receptor antagonism. ${ }^{12}$ Multiple effects on eosinophils, including chemotaxis, have been ascribed to histamine binding effects at $\mathrm{H}_{4}$ receptors. ${ }^{16}$ Antagonism of these effects by alcaftadine could account for the reduced eosinophil infiltration. Previous studies have shown that olopatadine is a potent mast cell stabilizer, ${ }^{17}$ so it is unlikely that the eosinophil inhibition demonstrated by alcaftadine is due to a heightened suppression of mast cell degranulation. Furthermore, if the mast cell stabilization profiles of olopatadine and alcaftadine were significantly different, then it follows that differences would have also been apparent in acute clinical signs and symptoms. Because this was not the case, it is possible that the eosinophil inhibition demonstrated by alcaftadine $0.25 \%$ is the result of an effect mediated via its broad spectrum of histamine receptor antagonism. Alternatively, higher doses of olopatadine may elicit similar effects on eosinophils as those observed with alcaftadine.

Alcaftadine $0.25 \%$ also demonstrated an ability to protect epithelial tight junction protein markers from allergic inflammation-based degradation. Conjunctival allergen challenge induced a loss in ZO-1 and E-cadherin expression in $\mathrm{S} / \mathrm{C}$ and vehicle-treated control groups. Both ZO-1 and E-cadherin levels were statistically superior to $\mathrm{S} / \mathrm{C}$ controls in the alcaftadine $0.25 \%$ treatment group. In contrast, olopatadine failed to prevent ZO-1 degradation, and was not significantly different from sensitized and challenged controls with regards to E-cadherin expression.

It is possible that the prevention of tight junction protein loss demonstrated by alcaftadine $0.25 \%$ is related to the ability of the compound to prevent eosinophil recruitment. Following chemotaxis, eosinophils release granular contents in the conjunctival epithelium. ${ }^{3}$ The release of toxic cellular products, including eosinophil cationic protein and eosinophil peroxidases, is known to cause additional tissue damage, resulting in what is viewed clinically as the "late-phase" allergic response (also known as a "late-phase reaction"). ${ }^{3}$ An in vitro study completed in an allergic asthma model found that presence of eosinophils in the respiratory epithelium led to reductions in E-cadherin expression, potentially contributing to disease pathogenesis. ${ }^{18}$ These results were supported by an in vivo study in a guinea pig model of nasal allergy which concluded that eosinophil recruitment was responsible for E-cadherin loss and that epithelial cell contact mediated by E-cadherin is loosened as a consequence of eosinophil infiltration. ${ }^{19}$ To date, no published work has discussed the implications of eosinophilia on tight junction markers in ocular allergy. However, the mechanistic similarities between these nasal and ocular allergic conditions support eosinophil inhibition as the mechanism by which alcaftadine protects the conjunctival epithelium. Further investigation into the mechanism of action of alcaftadine and its application for the treatment of human allergic diseases is warranted.

\section{Disclosure}

The authors report no conflicts of interest in this work.

\section{References}

1. Ciprandi G, Buscaglia S, Cerqueti PM, Canonica GW. Drug treatment of allergic conjunctivitis. A review of the evidence. Drugs. 1992;43: $154-176$.

2. Uchio E, Kimura R, Migita H, Kozawa M, Kadonosono K. Demographic aspects of allergic ocular diseases and evaluation of new criteria for clinical assessment of ocular allergy. Graefes Arch Clin Exp Ophthalmol. 2008;246:291-296.

3. Abelson MB, Smith L, Chapin M. Ocular allergic disease: Mechanisms, disease sub-types, treatment. Ocul Surf. 2003;1:127-149.

4. Aijaz S, Balda MS, Matter K, Kwang WJ. Tight junctions: Molecular architecture and function. In: International Review of Cytology. New York, NY: Academic Press; 2006.

5. Hughes JL, Lackie PM, Wilson SJ, Church MK, McGill JI. Reduced structural proteins in the conjunctival epithelium in allergic eye disease. Allergy. 2006;61:1268-1274.

6. Wan H, Winton HL, Soeller C, et al. The transmembrane protein occludin of epithelial tight junctions is a functional target for serine peptidases from faecal pellets of Dermatophagoides pteronyssinus. Clin Exp Allergy. 2001;31:279-294.

7. Runswick S, Mitchell T, Davies P, Robinson C, Garrod DR. Pollen proteolytic enzymes degrade tight junctions. Respirology. 2007;12: 834-842.

8. Abramowicz M, editor. Drugs for allergic disorders. Medical Letter Treatment Guidelines. 2010;8:9-18.

9. Rubenstein NM, Guan Y, Woo PL, Firestone GL. Glucocorticoid downregulation of RhoA is required for the steroid-induced organization of the junctional complex and tight junction formation in rat mammary epithelial tumor cells. J Biol Chem. 2003;278:10353-10360.

10. Salter M, Biggadike K, Matthews JL, et al. Pharmacological properties of the enhanced-affinity glucocorticoid fluticasone furoate in vitro and in an in vivo model of respiratory inflammatory disease. Am J Physiol Lung Cell Mol Physiol. 2003;293:L660-L667.

11. Bohets H, McGowan C, Mannens G, Schroeder N, Edwards-Swanson K, Shapiro A. Clinical pharmacology of alcaftadine, a novel antihistamine for the prevention of allergic conjunctivitis. $2011 \mathrm{~J}$. Ocul. Pharm Ther. In press. 
12. Gallois-Bernos A, Thurmond R. Alcaftadine, a new class of antihistamine with combined antagonist activity at $\mathrm{H}_{1}, \mathrm{H}_{2}$, and $\mathrm{H}_{4}$ histamine receptors. Personal communication.

13. Ohmori K, Hayashi K, Kaise T, et al. Pharmacological, pharmacokinetic and clinical properties of olopatadine hydrochloride, a new antiallergic drug. Jpn J Pharmacol. 2002;88:379-397.

14. Fukuishi N, Matsuhisa M, Shimono T, et al. Inhibitory effect of olopatadine on antigen-induced eosinophil infiltration and the LFA-1 and Mac-1 expression in eosinophils. Jpn J Pharmacol. 2002;88: 463-466.

15. Miyazaki D, Nakamura T, Ohbayashi M, et al. Ablation of type I hypersensitivity in experimental allergic conjunctivitis by eotaxin-1/ CCR3 blockade. Int Immunol. 2009;21:187-201.
16. Ling $\mathrm{P}$, Ngo $\mathrm{K}$, Nguyen $\mathrm{S}$, et al. Histamine $\mathrm{H} 4$ receptor mediates eosinophil chemotaxis with cell shape change and adhesion molecule up regulation. Br J Pharmacol. 2004;142:161-171.

17. Brockman HL, Momsen MM, Knudtson JR, Miller ST, GraffG, Yanni JM. Interactions of olopatadine and selected antihistamines with model and natural membranes. Ocul Immunol Inflamm. 2003;11: 247-268.

18. Terada N, Hamano N, Numata T, Konno A. Transepithelial migration of activated eosinophils induces a decrease of E-cadherin expression in cultured human nasal epithelial cells. Clin Exp Allergy. 2000;30: 807-817.

19. Kobayashi N, Dezawa M, Nagata H, Yuasa S, Konno A. Immunohistochemical study of E-cadherin and ZO1 in allergic nasal epithelium of the guinea pig. Int Arch Allergy Immunol. 1998;116:196-205.

\section{Publish your work in this journal}

Drug Design, Development and Therapy is an international, peerreviewed open-access journal that spans the spectrum of drug design and development through to clinical applications. Clinical outcomes, patient safety, and programs for the development and effective, safe, and sustained use of medicines are a feature of the journal, which has also been accepted for indexing on PubMed Central. The manuscript management system is completely online and includes a very quick and fair peer-review system, which is all easy to use. Visit http://www. dovepress.com/testimonials.php to read real quotes from published authors.

Submit your manuscript here: http://www.dovepress.com/drug-design-development-and-therapy-journal 